\title{
Perception evaluation kit: a case study with materials and learning styles
}

\author{
Ainoa Abella ${ }^{1,2}$ - María Araya León ${ }^{1,3}$ (D) . Lluís Marco-Almagro² ${ }^{(D)}$ \\ Laura Clèries Garcia ${ }^{1}$
}

Accepted: 4 June 2021 / Published online: 15 August 2021

(C) The Author(s), under exclusive licence to Springer Nature B.V. 2021

\begin{abstract}
Materials are elements that configure our built environment and are key components in design and engineering education. This research aims to understand learners' sensorial perception of materials as stimuli and what constitutes the most appropriate communication channel for learning about their characteristics without losing information in accordance with their VAK learning styles-visual, auditory and kinaesthetic-. Seventy-five people participated in this workshop. Using evaluation tools in a test format, they evaluated all the sensory properties of the following materials: Alusion ${ }^{\mathrm{TM}}$, PolarMoss, and Silkworms. These three materials were presented in various interaction formats, called channels: a text plus image-C1-, video-C2-, and a physical sample plus audio-C3-. Two types of experiments were carried out: mixed per person-interaction with the three materials in a different channel each time in random order-and blocked per person-interaction with the same material in the three channels, in an order of C1-C3. The data obtained was analysed using mixed models with the channel as a fixed factor and the individuals and material as the random factors. The most relevant results indicate significant differences between channels in accordance with the sensory property, normally $\mathrm{C} 2$ and $\mathrm{C} 3$. The level of responses between the two experiments is similar, therefore showing that the order $\mathrm{C} 1-\mathrm{C} 2-\mathrm{C} 3$ does not affect perception. Although the three learning styles-visual, auditory, and kinaestheticcoexist in the participants, the vast majority agree that they prefer $\mathrm{C} 3$ as easier to evaluate, more entertaining and the best way to learn.
\end{abstract}

Keywords Materials $\cdot$ Perception $\cdot$ Communication channels $\cdot$ Learning styles $\cdot$ Sensorial properties

Ainoa Abella

aabella@elisava.net

1 ELISAVA Barcelona School of Design and Engineering, ELISAVA Research, La Rambla 30-32, 08002 Barcelona, Spain

2 Universitat Politècnica de Catalunya-BarcelonaTech, Barcelona, Spain

3 University of Santiago, Chile, Santiago, Chile 


\section{Introduction}

Education has evolved and adapted to different contexts and societal realities. Nowadays, new learner-centred methods focusing on the best way to approach each individual and their own particular situations are crucial. Neuroscience research has shown that people learn better through emotions (Dirkx, 2011; LeDoux, 1992).

Emotions and the process of perceiving and internalizing knowledge vary with each individual (Tyng et al., 2017) and each of their learning styles. It is for this reason that more and more teachers are trying to use multiple resources and diversify formats.

In today's context, some non-face to face learning formats make it possible to provide a large variety of distance courses. This offers clear advantages for learning and accessible education yet poses a challenge in some areas such as concerns adapting content without losing important information.

When it comes to the formation of materials, studying and understanding the most adequate formats and tools for encouraging a more holistic transfer by combining technical and psychological properties is essential (Abella Garcia et al., 2019).

This study aims to contribute further data to be able to understand and answer the main research questions: How does the perception of the materials vary depending on the communication channel used? Is there a relationship between communication channels and learning styles?

\section{Theoretical framework}

\section{Learning styles}

Learning styles involve how the mind processes information through each individual's perceptions with the senses playing a primary role when absorbing and incorporating information from the surrounding environment. Despite the large body of research, there are some researchers and educators unconvinced of the learning styles benefits (Miller, 2001; Swanson, 1995). However, effective learning requires working based on each individual's different preferences and characteristics (Huang, 2019).

The way in which people receive information can be divided into three categories, also called modes, channels of perception or VAK-visual, auditory and kinaesthetic- (Dunn \& Dunn, 1978). Human beings use all three ways of processing information, but one is more developed for the large majority.

The reception of information in the brain becomes an important aspect in the learning process as this perception-understood as the process of capturing and processing the information received from the outside- gives rise to individual perceptual preference. Therefore, each human tends to largely use one of the three VAK perceptual modes as doing so improves their performance and helps them more easily learn the information (Cid et al., 2012).

These modes involve different predominate senses for collecting and processing information. The visual mode quite often uses the process of thinking in images. Useful resources for this mode include conceptual maps, videos, presentations, illustrations, photographs, summary tables, diagrams, among others (Medina-Velandia \& 
Plazas-Gómez, 2018; VARK Learn Limited, 2020) and normally with a preference for reading over listening (Mora et al., 2015).

With the auditory mode, the information is internalized through a process of sequential and organized listening. Guided readings, discussions, verbal instructions or explanations out loud are tools which help auditory people capture better (Medina-Velandia \& PlazasGómez, 2018; VARK Learn Limited, 2020). Moreover, people of this type more easily learn languages, imitate and speak to themselves. They find it more difficult to concentrate with background noise or sounds (Mora et al., 2015).

The kinaesthetic mode is the process by which information is acquired through sensations and movements. Some of the characteristics that differentiate it from the other two modes is a tendency to walk or move around to memorize information and a need for experiential learning; in other words, manipulating, experimenting, doing and feeling first-hand in order to understand and process information (Mora et al., 2015).

Each learning style is associated with a certain behaviour that fosters this information processing and, thus, the associated knowledge. According to Meza and Gómez (2008), visual people show organized, orderly, observant and calm behaviours, base everything on what they see and think through graphs, outlines and images. When the auditory mode is predominant, people have a way with words, remember what they hear and, thus, dialogues, talks, debates and sounds are elements that help them remember things. Finally, kinaesthetic learners learn by doing; in other words, by touching and through the sensations they feel.

Since the learning rate increases by personalizing content and thereby reducing the time necessary for learning to occur (Jafari \& Abdollahzade, 2019), learning styles make it possible to understand how each individual learns so as to get the most out of their capabilities and possibilities efficiently and constructively. One of the major challenges in teaching is providing knowledge as well as planning activities coherently and in a diversified way so that, based on their predominant mode, everyone may capture and gain further knowledge in a competent and effective manner.

\section{Educational formats, channels, and effectiveness}

University education has transformed and changed in recent decades. Active learning strategies are becoming more and more popular and common as they stimulate inquiry and interest as students acquire knowledge and skills (McCarthy \& Anderson, 2000). Moreover, they offer major benefits given that they are learner-centred, allow for greater participation and motivation and make topics more immediate and vivid by encouraging students to move beyond the surface and facts (Bonwell \& Eison, 1991; Ladousse, 1982; McCarthy \& Anderson, 2000; McKeachie, 2011).

Thanks to technological and digital progress and a rise in the demand for training, traditional physical classroom models with classical support material such as literature have begun to co-exist with other formats. Distance and digital education enable a transfer of knowledge that breaks from established criteria; in other words, virtual education is becoming an alternative that allows for more flexibility, in terms of time and space (SerratBrustenga \& Sunyer Lázaro, 2012 ). Nowadays, there are three types of communication channels used to transmit information when considering the user, the number of stimuli and the quantity of information received (Abella Garcia et al., 2019).

The three channels are as follows: 
- C1: texts and flat images like textbooks, articles and visual material, etc.

- C2: audiovisual material such as videos, virtual prototypes, resources with elements that are near-life size.

- C3: material or knowledge with which one can directly interact or are from a real context with which one can feel through the senses and by doing something.

The perceptions and emotional state resulting from the learning process are very different based on the channel used meaning a correct choice thereof is relevant. Likewise, combining communication channels with a learner's predominant learning style can foster and enable more effective knowledge absorption as the senses are better stimulated.

\section{Emotional learning in materials education}

Material selection when developing a design project is a fundamental unit of education in this field for the correct and coherent application thereof. For this purpose, there are different methods and ways to approach the complex nature of such selection considering the different characteristics of the materials from the most technical and objective to the sensorial, perceptual and emotional properties or the most subjective.

The more objective characteristics are what have been most studied and developed to date; however, the more subjective dimension of how materials are perceived is still being assessed and researched (Rognoli, 2010). Due to the complexity, grouping them into one universal language is difficult. Sensory properties and pertinent cultural associations are largely ignored in the development of new materials. The foregoing has revealed a need for change in education programs and a search for tools that offer references and translate subjective experiences with materials so as to transmit knowledge to students on how to manage and apply this emotional dimension to design (Wilkes et al., 2016). Some examples are data on textures and aesthetic values (Calvillo Cortés \& Falcón Morales, 2016; Rognoli, 2010; van Kesteren, 2008).

In particular, interaction with materials and physical samples during the learning process and design process is fundamental to obtaining information on the sensory, aesthetic and value properties(Karana et al., 2009). Many of the tools and methods that make it possible to obtain perceptual and emotional information are physical like materials libraries, for example. Due to the limitations of these resources, such as access to them and/or their cost, the use of other formats in the learning process with this sensorial and emotional dimension such as literature, virtual platforms and software is inevitable.

Nowadays, there are different virtual platforms and software programs that deliver information on materials - mostly technical- and innovation in this area. Added to the difficulty in accessing physical samples, all of the foregoing means understanding how all characteristics, especially those involving sensorial and emotional aspects, can be transmitted in virtual arenas without losing information is essential. Thus, the fundamental challenge is to continue exploring and researching these lines.

As part of the search and possible answers for understanding how the perception of materials varies based on the communication thereof, a workshop was carried out entitled "Perception Evaluation Kit: A Case Study with Materials". The aim of this case study is to determine the possible variation in the perception of materials based on the communication channel used in addition to the influence and distribution of the participants' learning styles and preferences for the different channels. On the other hand, the idea is to contribute further data and ideas on this issue. 


\section{Workshop methodology}

\section{Introduction to the workshop}

The workshop was carried out as part of the first-year subject Materials Physics in the Product Design Engineering undergraduate degree program at Elisava, Barcelona School of Design and Engineering. It was completed over four different sessions during the month of May 2019, following the four groups' timetables so the activity could be undertaken in smaller teams. The estimated duration was approximately 45 min with 25 min used for the assessment and another 10 for debate and discussion. The tools and procedures used were previously designed following the model of the first Perception Evaluation Kit: A Case Study with Materials workshop (Abella Garcia et al., 2019), considering some 100 students. The toolkit is comprised of: instructions for material interaction based on the class group, physical and digital channel support, a selection of physical materials, a Learning Style Test and a Perception Evaluation Card.

\section{Channels}

The channels used to transmit the information were:

- C1: A sheet for each material: An 80-115 word description was provided along with an image of the corresponding material (Fig. 1).

- C2: The video was shown in some cases on a computer see the section Participants, Materials and Procedures and Fig. 11-blocked per person- with the information projected on a screen for the rest-mixed per person. Each video shows general and detailed drawings of each material with a hand added to some drawings to provide information on the scale and sound. The video is a self-generated resource which was filmed - the explanation is given in English- and edited by the research team (Fig. 2).

- C3: An audio with a description of the material in English was presented in this channel. It was transmitted through earphones or speakers -blocked per person-while the person touched the physical sample or, in other cases, the audio was transmitted in general throughout the entire classroom. Just as with the video, the audios were recorded by the research team (Fig. 3).

Fig. 1 The material information sheet presented in channel 1. Source: (Abella Garcia et al. 2019)

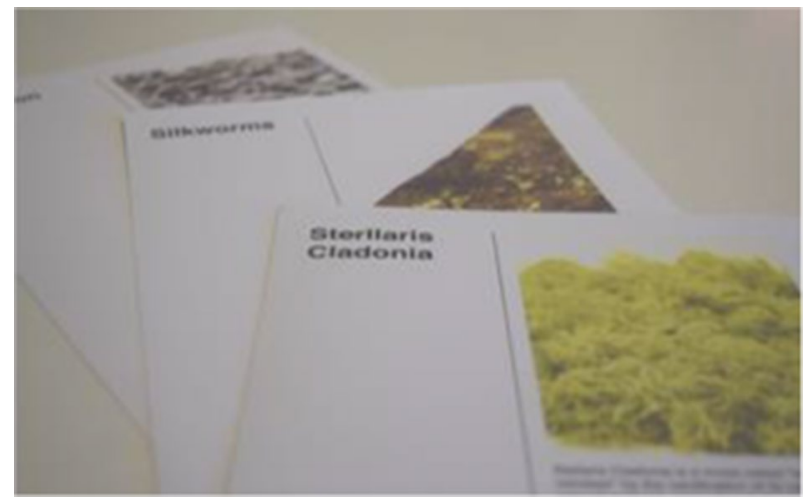


Fig. 2 Material presented in channel 2. Source: (Abella Garcia et al. 2019)

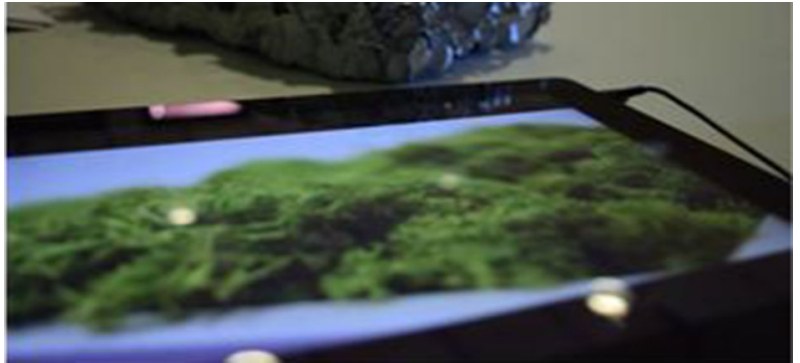

Fig. 3 Material available in channel 3. Source: (Abella Garcia et al. 2019)

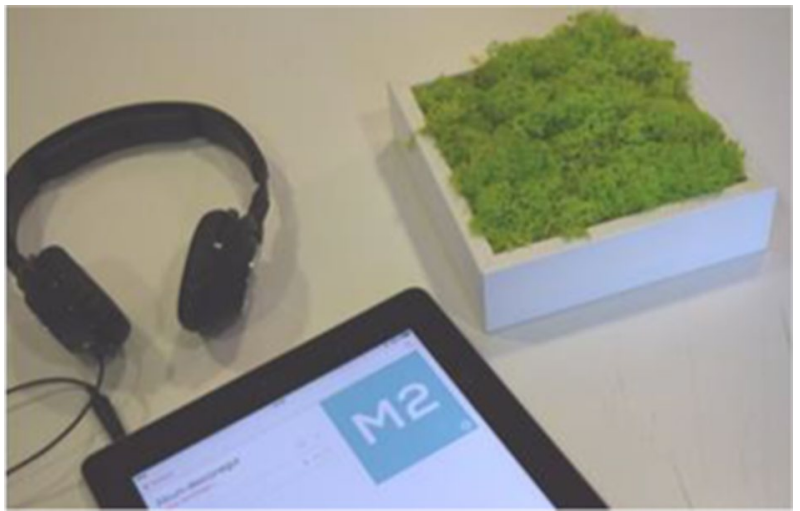

The characteristics of the information provided per material were the same in the three channels. The estimated reading time was previously calculated and added to the duration of the video $-\mathrm{C} 2-$ and audio $-\mathrm{C} 3-$.

Each channel worked is a reflection of the options available today for presenting and acquiring knowledge of materials. Channel $1-\mathrm{C} 1-$ represents textbooks, catalogues and datasheets, channel $2-\mathrm{C} 2$ - videos, much like what can be found on virtual platforms and channel $3-\mathrm{C} 3-$ is an approximate simulation of visits to specialized materials centres such as materials libraries where people can not only touch the materials but also get an explanation thereof.

\section{Material samples}

The materials chosen all have different sensory properties.

For identification purposes, the samples were numbered using the same system as the channels, M1, M2 and M3.

The first material -M1- was stabilized aluminium foam marketed under the brand name "Alusion" (Materfad n.d.). It was chosen because of how its characteristics are contrary to what is perceived. For example, the weight seems to be a heavy material yet it is actually light upon physical interaction. The texture is different from other metals and it makes a sound when in contact with other elements (Fig. 4).

M2 corresponds to PolarMoss (PolarMoss, n.d.) which is a natural moss. It was chosen because it is a rather surprising material to the touch which mixes natural aspects with 


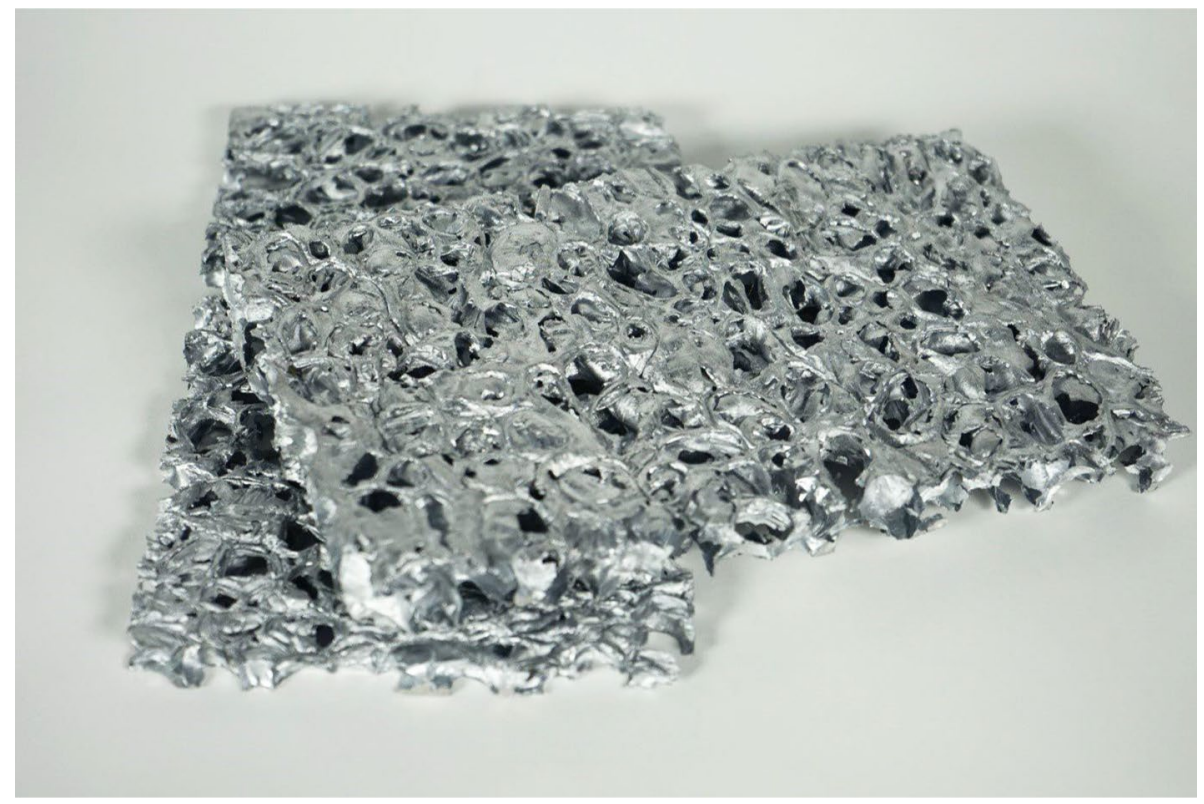

Fig. 4 M1 Alusion ${ }^{\mathrm{TM}}$ sample

various colours. Red, dark green and light green were used for the workshop. On the other hand, it offers sound absorption characteristics which are not obvious upon simple sight (Fig. 5).

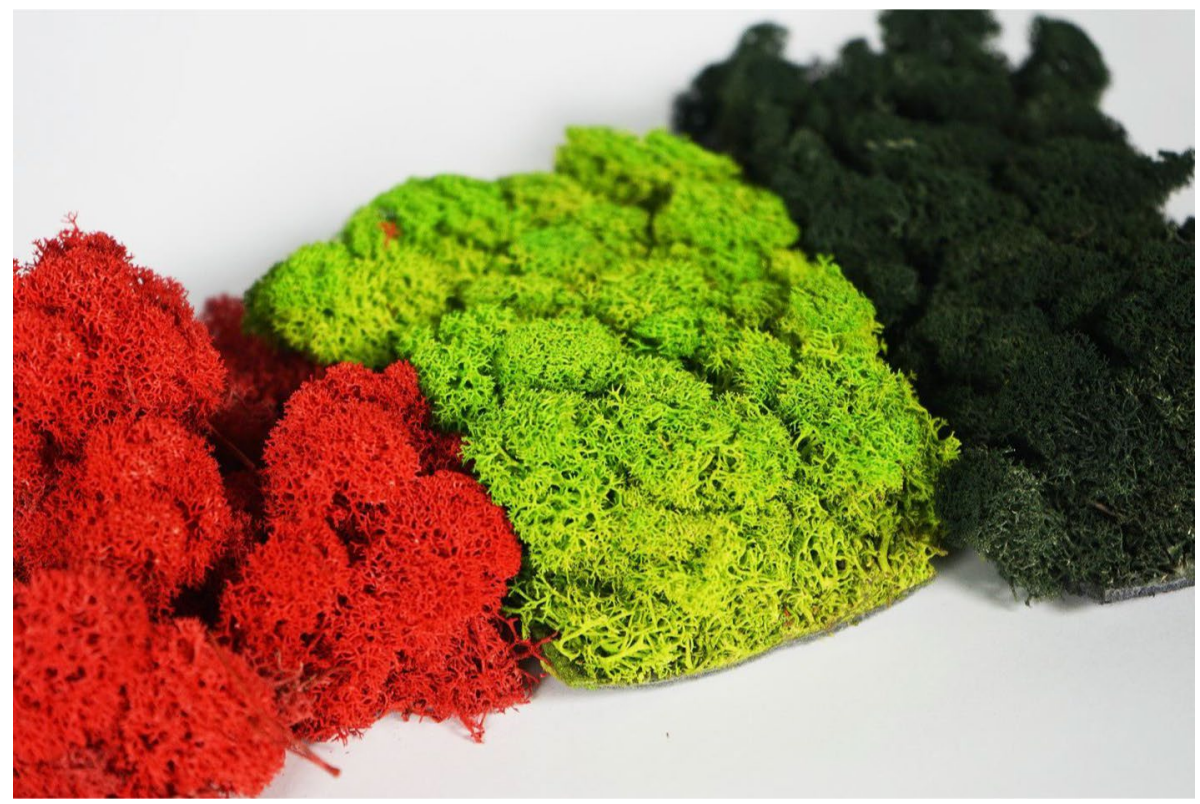

Fig. 5 M2 PolarMoss sample 
Finally, M3, Silkworm Cocoon (Huissoud, 2019) is a natural wood material with a leathery look. This material was chosen because of the predominant olfactory characteristics and unique texture; these properties differ based on the channel. It is worth mentioning that this material allows more exploration of properties related to smell and taste (Fig. 6).

\section{Perception evaluation card}

Printed Perception Evaluation Card (Abella Garcia et al., 2019) sheets were used to quantify the participants' perception based on the channel and material presented. This strategy not only eliminates dependence on technological devices, but also dependence on connection quality when using digital formats.

As can be observed in Fig. 7, a variant was considered related to two questions added to this workshop; they are included in order to understand possible associations and applications of the material.

\section{Learning style test}

A test with ten questions was used to classify the students' learning styles. Questions were selected from the article VAK Learning Styles Self-Assessment Questionnaire (Businessballs, 2019) which were directly related to the product so they were more significant and concordant with the students' backgrounds. The answers were mixed up so A was not always associated with visual, B with auditory and $\mathrm{C}$ with Kinaesthetic (Figs. 8, 9).

Moreover, three questions were added after the assessment of the three materials referring to the learning styles and communication channels. The questions were as follows:

Which channel did you find easier to evaluate all properties?

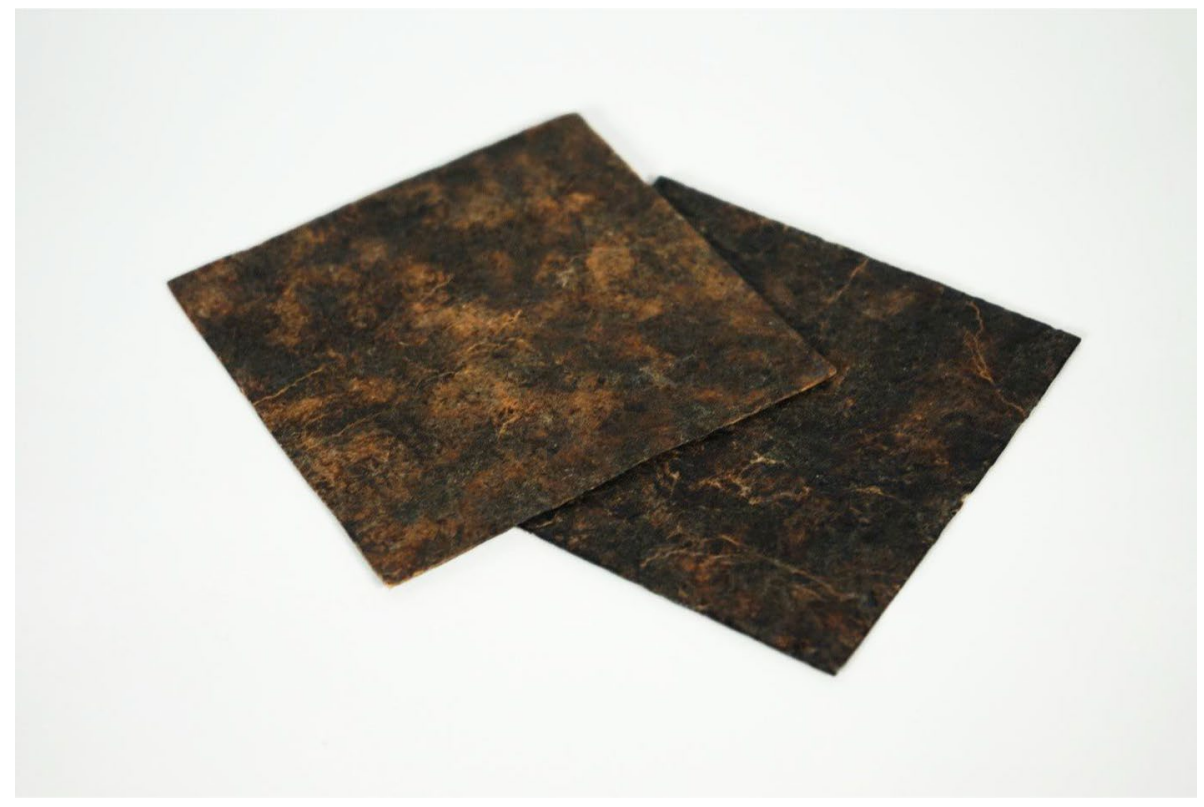

Fig. 6 M3 Silkworms material 


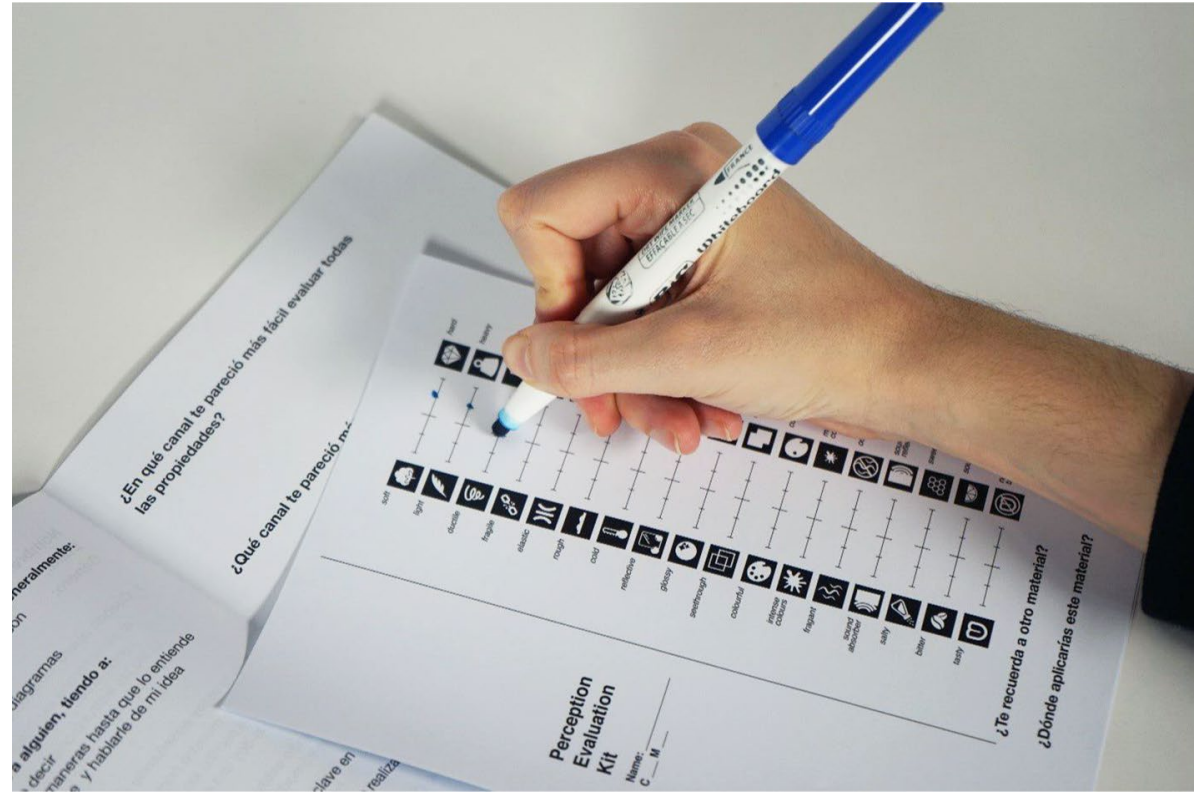

Fig. 7 Perception Evaluation Kit

Which channel did you find more entertaining?

Which channel did you most like for learning about the materials?

\section{Participants, materials, and procedures}

Seventy-five people participated in the workshop over four different sessions which were organized pursuant to their class timetables-session 1: 18 people, session 2: 17 people, session 3: 22 people and session 4: 18 people-. Each group/class reflects a pre-set order which is random and balanced for overall statistical validity and meaning.

The workshop proposes two different experiments: mixed per person and blocked per person.

- Mixed per person: The participating students interact with a different material through each channel, see Fig. 10. This experiment was carried out over the first three sessions and each group/class interacted with the three materials, one per channel without repeating any material sample. One may observe that each group/class reflects the same order as far as the channel yet not in relation to the samples. This was done to provide overall balance.

- Blocked per person: The participating students were divided into three smaller groups. These groups were defined and assigned a material -M1, M2 or M3-. Depending on the material sample defined for each group, the specific material was presented in the three different channels beginning with $\mathrm{C} 1$, then $\mathrm{C} 2$ and finally, $\mathrm{C} 3$-opening up the channel and expanding upon the quantity of information received- (see Fig. 11). 


\section{Name:}

Age:

\section{Gender:}

\section{When I operate new equipment I generally:}

a) listen to an explanation from someone who has used it before

b) read the instructions first

c) go ahead and have a go, I can figure it out as I use it

2. If I am teaching someone something new, I tend to:
a) demonstrate first and then let them have a go
b) write instructions down for them
c) give them a verbal explanation

3. When I am learning a new skill, I am most comfortable:
a) watching what the teacher is doing
b) talking through with the teacher exactly what I'm supposed
to do
c) giving it a try myself and work it out as I go

\section{When I concentrate, I most often:}
a) focus on the words or the pictures in front of me
b) move around a lot, fiddle with pens and pencils and touch things
c) discuss the problem and the possible solutions in my head

\section{My first memory is of:}
a) doing something
b) being spoken to
c) looking at something

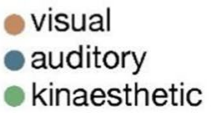

Fig. 8 Learning Styles Test, part 1, with an internal answer guide for tutors or researchers

There are different steps in the workshop and the monitoring thereof makes it possible to perform the complete activity. Firstly, the students answered the Learning Style Test and then assessed the materials with the Perception Evaluation Kit as per the experimental design and order assigned. After interacting with the material, the students completed the Perception Evaluation Card. The participants can choose to either fill in all of the 
6. When I have to revise for an exam, I generally:

a) talk over my notes, alone or with other people

b) imagine making the movement or creating the formula

c) write lots of revision notes and diagrams

\section{If I am explaining to someone I tend to:}

a) show them what I mean

b) explain to them in different ways until they understand

c) encourage them to try and talk them through my idea as they do it

\section{I find it easiest to remember:}
a) faces
b) things I have done
-c) names

\section{I remember things best by:}
a) saying them aloud or repeating words and key points in my head
b) doing and practising the activity or imagining it being done
oc) writing notes or keeping printed details

\section{If I have to complain about faulty goods, I am most comfortable:}
a) writing a letter
b) complaining over the phone
c) taking the item back to the store or posting it to head office

Fig. 9 Learning Styles Test, part 2, with an internal answer guide for tutors or researchers

Fig. 10 Mixed per person experiment

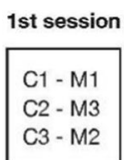

$\mathrm{n}=18$ 2nd session

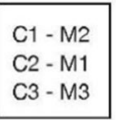

$\mathrm{n}=17$ 3rd session

C3 - M1

$n=22$ 
Fig. 11 Blocked per person experiment

\section{4th session}

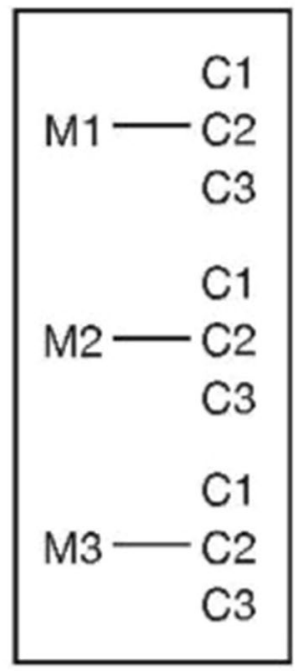

$\mathrm{n}=18$

properties or leave some blank if they do not know or are not sure. Once the entire itinerary is finished-a complete assessment- the three questions on the channels and learning are answered. All the tests-Learning Style Test and Perception Evaluation Kit- were returned and a debate and reflection period began with further interaction with all the available physical samples.

There were 2 workshop tutors to explain and conduct the activity for proper implementation of the workshop, except for the last session-a blocked per person experimental design — when there were 3 so that one could be available for each group.

\section{Findings}

\section{Material perception per channel}

One of the aims of the research is to determine how perception of a material changes based on the communication channel used. In other words, whether the perception of the materials is different based on $\mathrm{C} 1, \mathrm{C} 2$ or $\mathrm{C} 3$. Two different experimental types were used with this case study: mixed per person and blocked per person. With the first, the material samples by channel were different while with the second, the material was always the same. The following sections explain the findings.

\section{Mixed per person}

The participant analysis followed the distribution shown in Fig. 10, applying mixed models with the channel as a fixed factor and the individuals and the material as random factors. The findings indicate significant differences between channels as per the pair of 
Fig. 12 First cluster of sensory properties

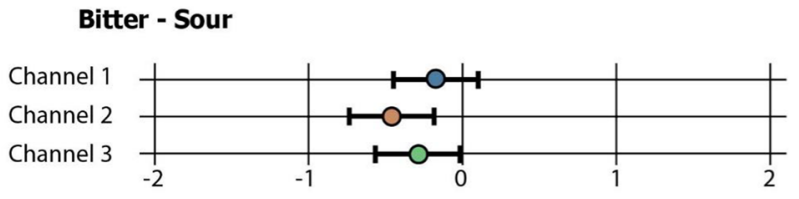

Glossy - Matte

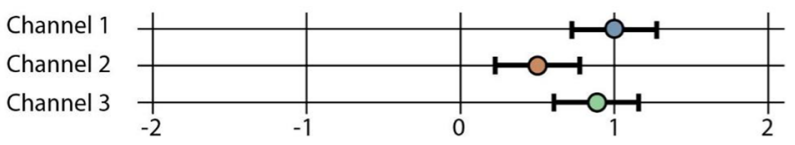

Tasty - Not Tasty

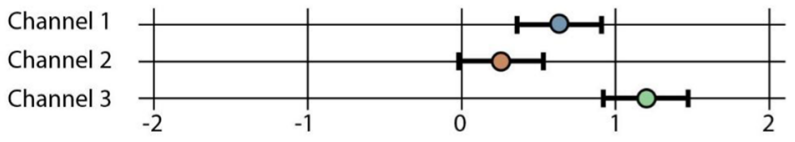

Fragant - Odorless

Fig. 13 Second cluster of sensory properties

\section{Light - Heavy}

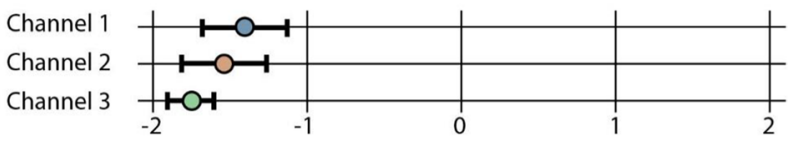

properties assessed in the large majority of the cases except for six properties. What follows are the detailed findings in Figs. 12-17, grouped by similarity in the results.

The properties presented in Fig. 12 are related to the senses of taste and sight. C2 stands out over the other two as the properties reflect perception scores in this channel which are a bit lower; in other words, there is a slight inclination for the opposite property -corresponding to scores with a negative value-.

Upon observing Fig. 13, the properties show a common pattern as the scores for perception gradually drop from $\mathrm{C} 1$ to $\mathrm{C} 3$. For the light-heavy property in this step from $\mathrm{C} 1$ to $\mathrm{C} 2$, the result moves from lighter to the highest value. However, the idea of the smell of the materials is reaffirmed under the fragrant-odourless property.

In accordance with the information presented in Fig. 14, the three channels show gradually increasing scores from a more negative tendency to a more neutral one - 0 - in C3. The salty-sweet pair stands out in $\mathrm{C} 2$ in comparison with $\mathrm{C} 1$ and $\mathrm{C} 3$.

As concerns the properties presented above, C1 stands out in Fig. 15 with more positive values with respect to $\mathrm{C} 2$ and $\mathrm{C} 3$ which show more similar scores between them. 
Fig. 14 Third cluster of sensory properties

Fig. 15 Fourth cluster of sensory properties

Fig. 16 Fifth cluster of sensory properties

\section{Rough - Smooth}

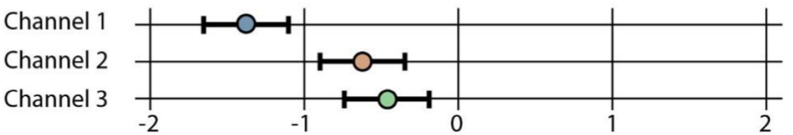

Salty - Sweet

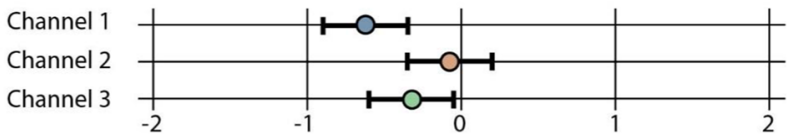

\section{Seethrough - Opaque}

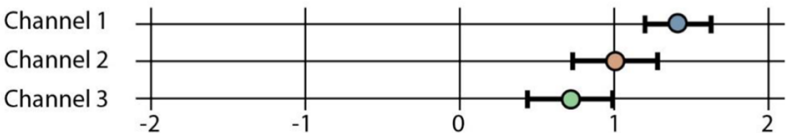

Elastic - Not Elastic

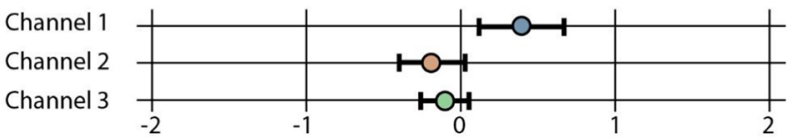

Fragile - Strong

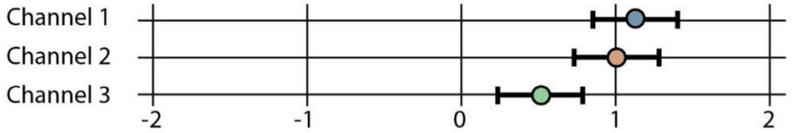

Sound absorber - Sound reflector

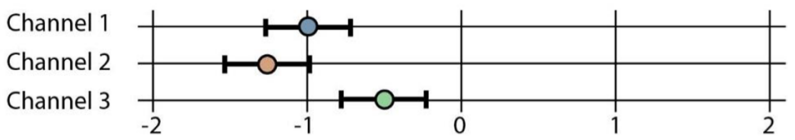

In channel 1, the materials are perceived as more opaque and non-elastic whereas the values are closer to neutral in the other channels.

In this Fig. 16, two pairs of properties show significant differences between channels but do not share a similar pattern with any other property. On the one hand, the fragile-strong property in $\mathrm{C} 3$ is different from the others as the materials score as a bit less strong in this one. Yet the sound absorbent-sound reflector pair is different from the others in $\mathrm{C} 3$ as well.

The final cluster of sensory properties (see Fig. 17) reflects those which do not show any significant differences between channels. In other words, the scores are similar between $\mathrm{C} 1, \mathrm{C} 2$ and $\mathrm{C} 3$. These properties are related to the senses of sight and touch and 
Fig. 17 Final cluster of sensory properties

\section{Cold - Warm}

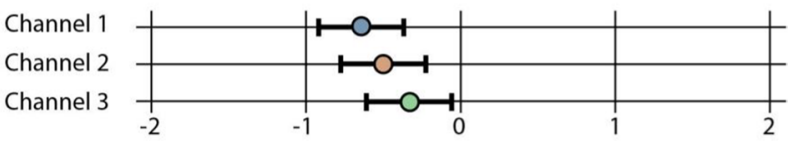

Ductile - Tough

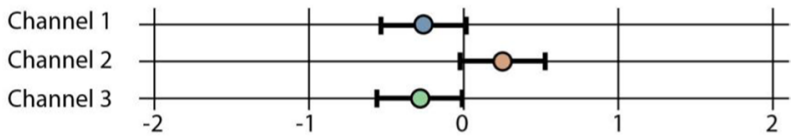

Colourful - Colourless

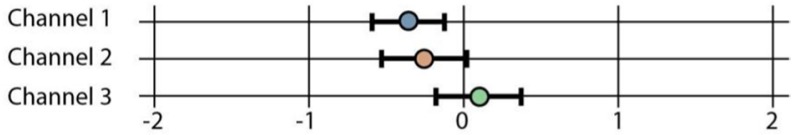

Intense colours - Mild colours

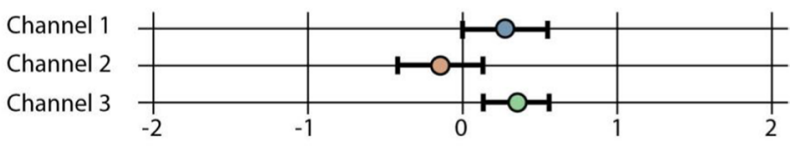

Reflective - Not Reflective

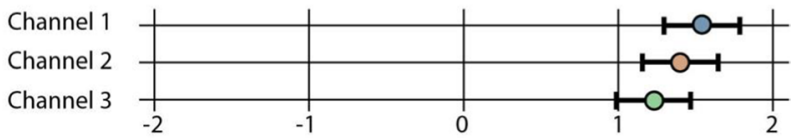

Soft - Hard

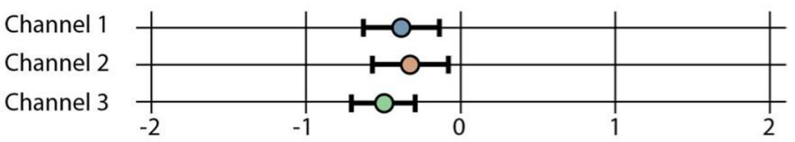

the participants are likely more familiar with unconsciously assessing them in elements of daily interaction.

\section{Blocked per person}

The participant analysis followed the distribution shown in Fig. 11, applying mixed models with the channel as a fixed factor and the individuals and the material as random factors. The findings indicate significant differences between channels as per the pair of properties assessed in most of the cases except with five properties -Fragile-Strong, 
Colourful-Colourless, Intense colours-Mild colours, Reflective-Non Reflective and Soft-Hard-.

Figure 18 shows the results of the scores for each pair of properties as per the two experiment types. In the previous section -mixed- the sensory properties were grouped based on the patterns reflected. In the case of the blocked per person experiment, four clusters can be distinguished due to their similar results.

Firstly, the properties that reflect significant differences in channel 3 are: BitterSour, Fragrant-Odourless, Light-Heavy, Rough-Smooth, Transparent-Opaque and Tasty-Bland. There are two other property pairs, Ductile-Tough and Sound absorbent-Sound insulating, where C3 is also different in comparison with the others yet the responses show another pattern. This horizontal mirrored pattern is the one that reflects the perception results for Cold-Warm. On the other hand, C2 is statistically significant

\section{Randomized by person}
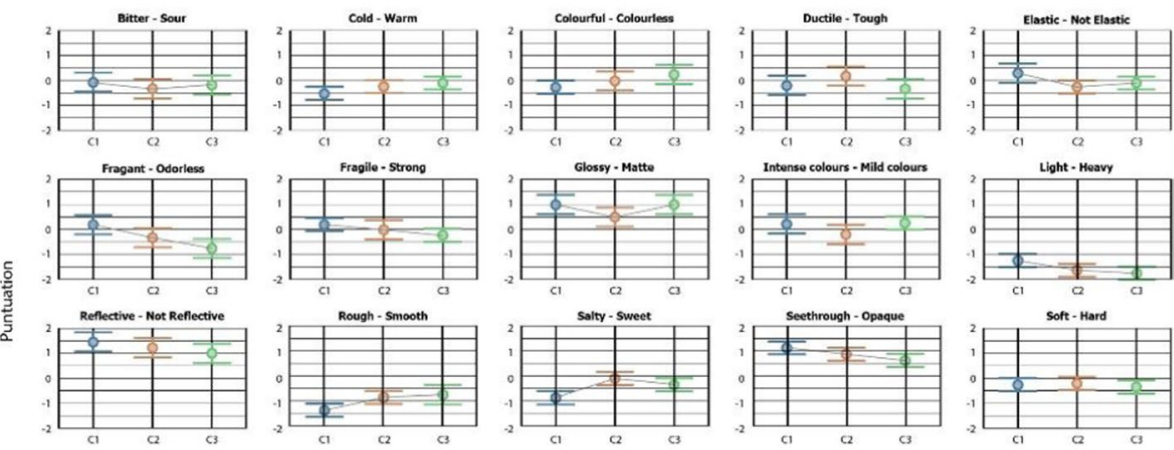

Light - Heavy

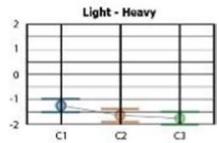

Rough - Smooth
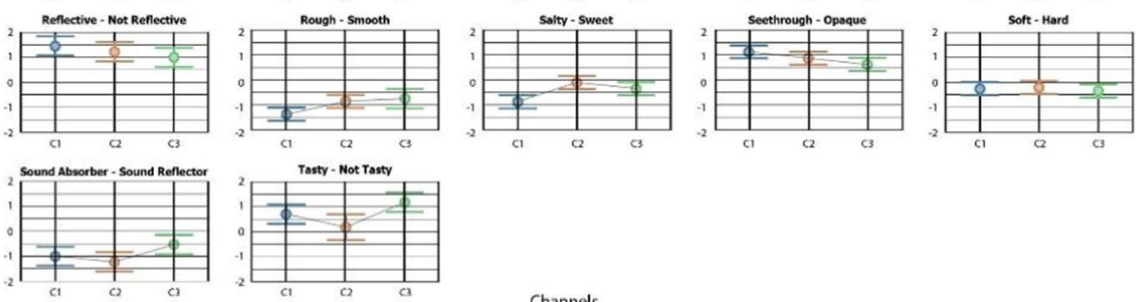

Channels

\section{Block by person}
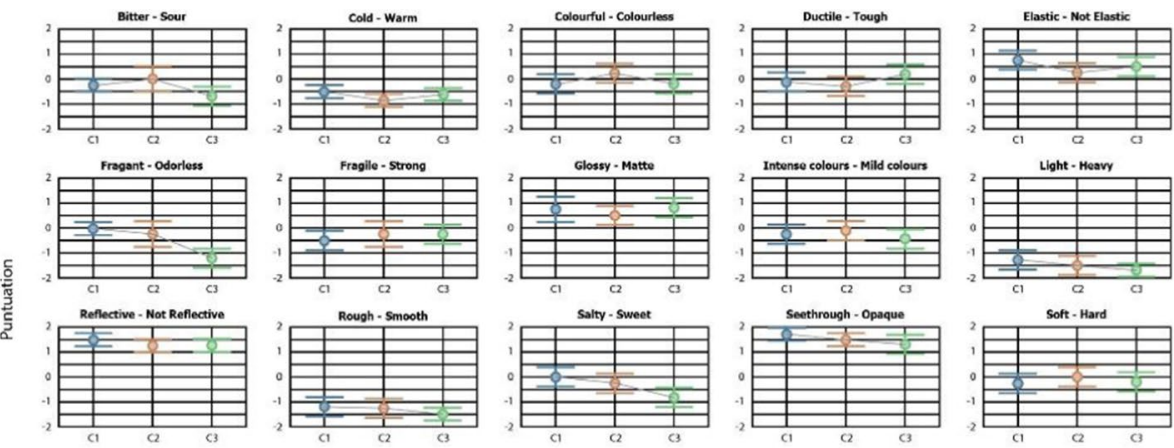

Light - Moavy

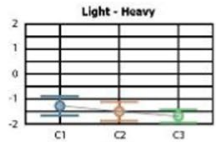

Rough - Smooth
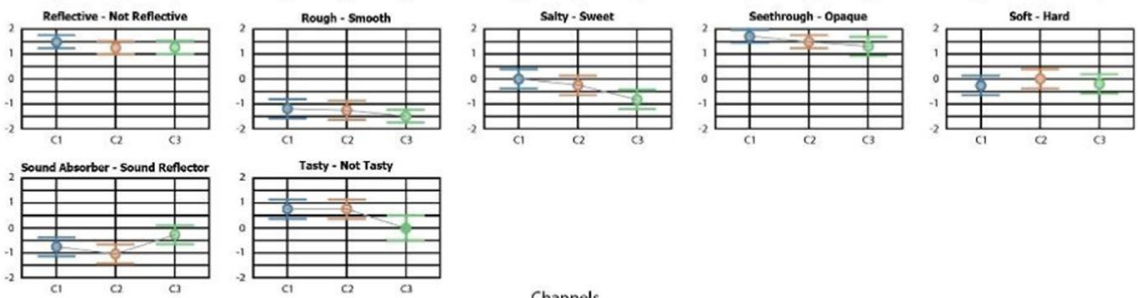

Channels

Fig. 18 Comparison of the scores of properties as per the experiment type 
in comparison with $\mathrm{C} 1$ and $\mathrm{C} 3$ with respect to Elastic-Non Elastic and reflects the same horizontal rotated pattern for Colourful-Colourless. Finally, five pairs of properties showed no differences between channels: Fragile-Strong, Glossy-Matte and Intense colours-Mild colours, Reflective-Non Reflective and Transparent-Opaque.

\section{Learning styles and communication channels}

Another aim of this case study was to determine the distribution of the participants' learning styles as well as understand the preferences and use of the communication channels for presenting information on materials. As mentioned above, three different items were evaluated with respect to a preference for communication channels: the ease of assessing all the properties, how entertaining it was and the pleasure in learning.

Figure 19 below shows the distribution of visual, auditory and kinaesthetic learning styles in the entire group of participants. As can be seen, a large majority reflect a combination of the VAK perceptual modes although there are clear differences between them. Two learning styles are predominant in some participants whereas three co-exist in others.

The participants' visual, auditory and kinaesthetic percentages were recoded as follows to use a Chi-Square test to verify the possible relationship between channels and learning styles, see Table 1.

After obtaining the adjusted percentages with the new values, a Chi-square test was done to find any possible relationship between learning styles and the channel perceived as easiest for assessing all the properties -easy -, more entertaining -entertaining- and the one the participants liked the most for learning about materials -learning-.

No statistically significant relationship was observed for the visual learning stylewith a level of significance of 5\%-. However, findings of interest were obtained when the study was done with auditory and kinaesthetic learnings styles.

Although the large majority of people see channel 3 as easier and more entertaining, there is a significant difference in preference for channels 1 and 2 for the easier and more entertaining criteria among people with a high auditory style level with respect to those with a low auditory style level. People with a high auditory style level perceive channels 1 or 2 as easier - p-value $=0.006$ - and more entertaining - p-value $=0.028-$.

Finally, it is important to highlight the existence of a significant association -at a level of significance of 10\%- among the perception of a more entertaining channel and a low or high kinaesthetic learning style level with a p-value of 0.054. Even though most of the people perceive channel 3 as more entertaining, some people with low kinaesthetic learning style levels perceive channels 1 and 2 as more entertaining $-\mathrm{p}$-value $=0.054-$.

\section{Discussion}

Since the aim of this case study is to determine the possible variation in the perception of materials based on the communication channel used in addition to the influence and distribution of the participants' learning styles and preferences for the different channels, the most relevant findings are presented below. 


\section{Learning Styles VAK}

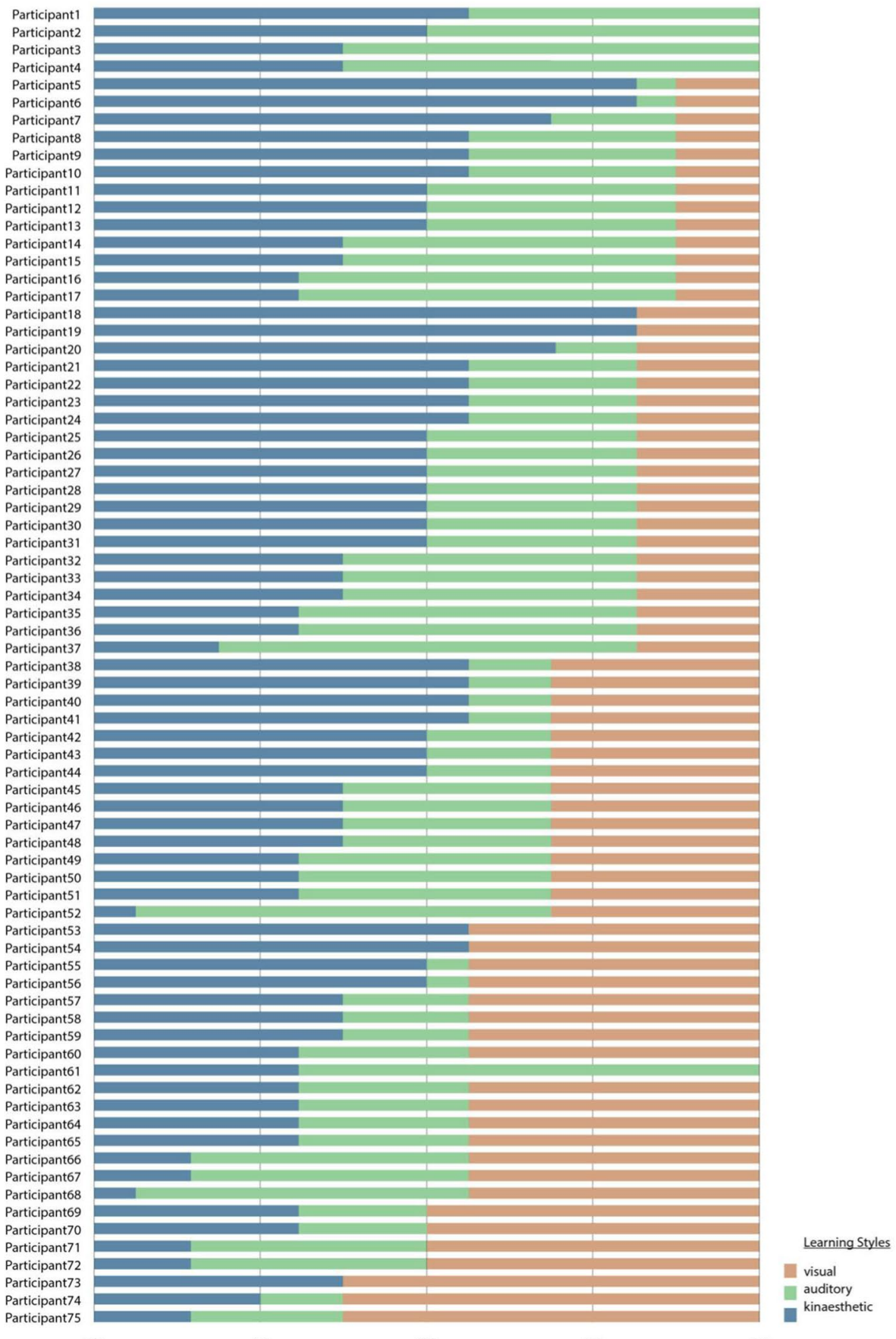

Fig. 19 Distribution of learning styles among participants 
Table 1 Recoding of learning styles

\begin{tabular}{lll}
\hline Learning style & Low & High \\
\hline Visual & Between 0 (minimum) and 2 & Between 3 and 6 (maximum) \\
Auditory & Between 0 (minimum) and 2 & Between 3 and 6 (maximum) \\
Kinaesthetic & Between 1 (minimum) and 4 & Between 4 and 8 (maximum) \\
\hline
\end{tabular}

\section{Material perception as per the channel}

Significant differences were observed between the communication channels used to transmit the information -physical, sensory and emotional properties- through materials, as shown by the findings in Figs. 12-17. This case study used two experimental types -mixed and blocked- in a view to understanding any differences when the channels are presented randomly or in a pre-set order $\mathrm{C} 1, \mathrm{C} 2$ and $\mathrm{C} 3$-thereby expanding the channels and the quantity of stimuli provided-.

The findings were grouped based on the patterns shown by the scoring for the two types of experiments. Likewise, there are pairs of properties that coincide in the findings between the two experiments. On the one hand, those that show statistically significant differences with similar findings patterns such as: Elastic-Non Elastic, Sound absorbentSound insulating. And on the other hand, the properties where there are no differences between channels and the findings can be observed in the two experiments: Light-Heavy, Glossy-Matte and Reflective-Non Reflective. In the two cases, the channels where these significant differences appear with respect to the others are C2 -video- and C3 -physical sample- depending on the specific sensory property in the materials being assessed.

Upon comparing the findings from the two experiments, similarities are detected as concerns the values assigned as per the pair of properties; in other words, a large majority of the findings are in the same band -positive, neutral or negative values- both in mixed per person and blocked per person. The conclusion is that the level of the response is not so different between the mixed experiment and the blocked experiment.

This statement gives rise to another relevant conclusion. Upon analysing the graphs in detail, the findings show that expanding and opening up a channel -following the order of $\mathrm{C} 1, \mathrm{C} 2$ and then $\mathrm{C} 3-$ does not affect the people's perception much. Thus, the participants score and perceive the material as per the quantity of stimuli and information delivered by the specific communication channel without the order thereof affecting their perception and respective assessment. In other words, if a person perceives a material in C3 in a certain way, the sensorial assessment continues to be the same irrespective of whether interaction with it takes place in the first or final step.

\section{Learning styles and communication channels}

Learning styles help determine the way in which participants learn or rather detect, collect and remember knowledge better (Cid et al., 2012). The distribution of learning styles co-exist in this case study with the three modes -auditory, visual and kinaesthetic- in all participants except nine people. Of these, four reflect a combination of kinaesthetic and auditory learning styles whereas the others maintain kinaesthetic with visual. 
The participants' learning styles may correlate with a more adequate communication channel for capturing information, thus fostering and promoting better use of their capabilities and possibilities (Huang, 2019). To understand any preference for communication channels, three criteria were established: easier to assess the properties, more entertaining and more pleasurable for their learning. The findings show a clear preference for $\mathrm{C} 3$ among all of them, although there are a few exceptions. As concerns the easier criteria, five people prefer $\mathrm{C} 1$ - sheet- and five, $\mathrm{C} 2$-video-. With respect to more entertaining, two participants show a preference for $\mathrm{C} 1$ and four for $\mathrm{C} 2$. Finally, as far as exceptions in learning styles, nine people like $\mathrm{C} 1$ better and six, $\mathrm{C} 2$. This again shows that people prefer interacting with physical samples.

According to the literature mentioned in the theoretical framework, learning styles and communication channels can be related based on the stimuli provided in the following way: the visual style with $\mathrm{C} 1$-sheet-, auditory with $\mathrm{C} 2$-video- and kinaesthetic with $\mathrm{C} 3$ -physical sample-. In any case, this study shows that people prefer $\mathrm{C} 3$ whenever possible in comparison with the other channels. This is due to the fact that $\mathrm{C} 3$ allows complete interaction among all senses as indicated by Karana et al. (2009), and therefore, suits all learning styles in one way or another. Even still, this research reflects significant differences in channel preference for the entertaining and/or easy criteria depending on the high or low auditory and kinaesthetic level. People with a low level kinaesthetic learning style find $\mathrm{C} 1$ and $\mathrm{C} 2$ more entertaining. This finding coincides with those with high levels of the auditory style as they also perceive $\mathrm{C} 1$ and $\mathrm{C} 2$ as easier and more entertaining.

\section{Conclusion}

The purpose of this research is to determine how perception of a material changes based on the communication channel used as well as the relationship between communication channels and learning styles.

This study proves that communication channels significantly influence the perception of materials as far as some properties. The order of channel presentation, whether a visual interaction $\mathrm{C} 1$, auditory $\mathrm{C} 2$ or complete $\mathrm{C} 3$, do not change the user's perceptual assessment. In any case, there continues to be a tendency to prefer the channel that allows complete interaction with the physical sample.

A further aim is to contribute to the search for new ways of transmitting sensorial and emotional information from materials in today's resources and context. This need has become even more evident with the current education situation caused by the COVID19 pandemic and the need to virtualize the different areas of learning under the New Normality.

Materials are elements with which people interact and which are a part of our daily lives. Therefore, understanding them in a holistic manner -sensory and technical properties- will help reinforce learning and teaching processes in these fields, foster their correct application and enable innovation in the field of materials. All of this first involves reassessing the sensory properties of the materials in the formation process. This research intends to open up a means for assisting with this new search for ideal formats given that it has been proven that sensory properties and the assessment thereof vary based on the channel. Moreover, different experiment types were proposed and tested in addition to tools for understanding the ways in which people learn such as VAK learning styles, for example. 
These resources and hybrid methods are valuable since they offer more data and perspectives in order to build an enriched and more varied research context.

Through the Perception Evaluation Kit workshop and the design-based research methods, further data have been contributed to the relationship between human perception and communication channels for transmitting information. The research presented could be extrapolated to other areas of knowledge transfer and learning beyond materials in order to determine the best channel or combination of channels for transmitting information. Of course, new and emerging formats such as videos with better image and sound quality, virtual reality and simulations of current contexts must always be taken into account.

\section{References}

Abella Garcia, A., Araya León, M. J., Clèries Garcia, L., \& Marco-Almagro, L. 1. (2019). Perception evaluation Kit: A case study with materials. The International Journal of Design Education, 13(4), 69-88. https://doi.org/10.18848/2325-128X/CGP/v13i04/69-88.

Bonwell, C. C., \& Eison, J. A. (1991). Active learning; creating excitement in the classroom. ASHE-ERIC Higher Education Report No. 1. Washington, D.C.: The George Washington University, School of Education and Human Development.

Businessballs. (2019). VAK learning styles. Retrieved from https://www.businessballs.com/self-awareness/ vak-learning-styles-self-test/\#vak-learning-styles.

Calvillo Cortés, A. B., \& Falcón Morales, L. E. (2016). Emotions and the urban lighting environment: A cross-cultural comparison. SAGE Open, 6(1), 2158244016629708. https://doi.org/10.1177/21582 44016629708

Cid, F. M., Suazo, A. G., Ferro, E. F., \& Aguilera González, J. (2012). Estilos de Aprendizaje Visual, Auditivo o Kinestésico de los Estudiantes de Educación Física de la UISEK de Chile. Revista Electrónica De Psicología Iztacala, 15(2), 405-415.

Dirkx, J. M. (2011). The meaning and role of emotions in adult learning. Educational and Child Psychology, 28(1), 77-88. https://doi.org/10.1002/ace

Dunn, R., \& Dunn, K. (1978). Teaching students through their individual learning styles. Prentice Hall.

Huang, T. C. (2019). Do different learning styles make a difference when it comes to creativity? An empirical study. Computers in Human Behavior, 100, 252-257. https://doi.org/10.1016/j.chb.2018.10.003

Huissoud, M. (2019). Silkworms. Retrieved from http://www.marlene-huissoud.com/from-insects-silkw orms/.

Jafari, S. M., \& Abdollahzade, Z. (2019). Investigating the relationship between learning style and game type in the game-based learning environment. Education and Information Technologies. https://doi. org/10.1007/s10639-019-09898-Z

Karana, E., Hekkert, P., \& Kandachar, P. (2009). Meanings of materials through sensorial properties and manufacturing processes. Materials and Design, 30(7), 2778-2784. https://doi.org/10.1016/j.matdes. 2008.09.028

Ladousse, G. P. (1982). Role play and simulation in language learning. Simulation/games for Learning, $12(2), 51-60$.

LeDoux, J. E. (1992). Brain mechanisms of emotion and emotional learning. Current Opinion in Neurobiology, 2(2), 191-197. https://doi.org/10.1016/0959-4388(92)90011-9

Materfad. (n.d.). Alusion. Retrieved from http://es.materfad.com/material/803/alusion.

McCarthy, J. P., \& Anderson, L. (2000). Active learning techniques versus traditional teaching styles: Two experiments from history and political science. Innovative Higher Education, 24(4), 279-294. https:// doi.org/10.1023/b:ihie.0000047415.48495.05

McKeachie, W. J. (2011). Teaching tips: Strategies, research, and theory for college and university teachers. Wadsworth, Cengage Learning.

Medina-Velandia, L. N., \& Plazas-Gómez, L. A. (2018). Agentes Inteligentes y Modelo VARK, proponen Estrategias de Aprendizaje según la Manera en que Asimila un Individuo. Revista Educación en Ingeniería, 13(26), 11-19. https://doi.org/10.26507/rei.v13n26.878.

Meza, M., \& Gómez, B. (2008). Estilos de Aprendizaje y Rendimiento Académico en los y las Estudiantes de la Institución Educativa Carlota Sánchez de la Ciudad de Pereira (Final degree thesis). Retrieved from http://repositorio.utp.edu.co/dspace/handle/11059/985. 
Miller, P. (2001). Learning styles: The multimedia of the mind. Research Report.

Mora, M. C. G., Martínez, J. J. B., \& González, J. P. C. (2015). Caracterización de Estilos de Aprendizaje y Canales de Percepción de Estudiantes Universitarios. Opción, 31(3), 509-527.

Pekrun, R., Goetz, T., Titz, W., \& Perry, R. P. (2002). Academic emotions in students' self-regulated learning and achievement: a program of qualitative and quantitative research. Educational Psychologist, 37(2), 91-105. https://doi.org/10.1207/S15326985EP3702_4

PolarMoss. (n.d.). PolarMoss. Retrieved from de https://www.polarmoss.fi/.

Rognoli, V. (2010). A broad survey on expressive-sensorial characterization of materials for design education. METU Journal of Faculty of Architecture, 27(2), 287-300. https://doi.org/10.4305/METU.JFA. 2010.2.16

Serrat-Brustenga, M., \& Sunyer Lázaro, S. (2012). El Centro de Recursos Para el Aprendizaje y la Investigación (Crai) en Permanente Transformación: Servicios y Recursos para el Nuevo Usuario 2.0. Universitat Politècnica de Catalunya. Servei De Biblioteques i Documentació, 3, 1-10.

Swanson, L. J. (1995). Learning styles: A review of the literature. The Clarmont Graduate School. ERIC Document Reproduction Service No 387067.

Tyng, C. M., Amin, H. U., Saad, M. N. M., \& Malik, A. S. (2017). The influences of emotion on learning and memory. Frontiers in Psychology, 8, 1454. https://doi.org/10.3389/fpsyg.2017.01454

van Kesteren, I. E. H. (2008). Product designers' information needs in materials selection. Materials and Design, 29(1), 133-145. https://doi.org/10.1016/j.matdes.2006.11.008

VARK Learn Limited. (2020). The VARK Modalities. Retrieved from https://vark-learn.com/introductionto-vark/the-vark-modalities/.

Wilkes, S., Wongsriruksa, S., Howes, P., Gamester, R., Witchel, H., Conreen, M., et al. (2016). Design tools for interdisciplinary translation of material experiences. Materials \& Design, 90, 1228-1237. https:// doi.org/10.1016/j.matdes.2015.04.013

Publisher's Note Springer Nature remains neutral with regard to jurisdictional claims in published maps and institutional affiliations. 